\title{
UNA EXPERIENCIA DE RIESGO. Efecto colateral del trabajo de campo etnológico en tiempos modernos
}

\author{
Ángel ACUÑ̃ DELGADO \\ Universidad de Granada (España) \\ acuna@ugr.es
}

\section{AN EXPERIENCE OF RISK. Side effect of ethnological field work in modern times}

Resumen: El trabajo de campo etnográfico, como rasgo distintivo de la Antropología, implica habitualmente salir de las bibliotecas y situarse en contexto de interacción con las personas que son motivo de interés. En algunos manuales metodológicos se advierte de los riesgos que supone estrechar las distancias y sumergirse por tiempo prolongado en la vida de un grupo social, pero, por razonas obvias, no se refieren las numerosas situaciones peligrosas que se pueden dar o se han dado en los prolegómenos, antes de entrar o después de salir del lugar de trabajo. En el presente texto presentamos un caso concreto de experiencia vivida en Venezuela en enero de 2006 con motivo de un atraco con secuestro justo al llegar al país con el propósito de realizar trabajo de campo en el Alto Orinoco con comunidades Yanomami. La narración tiene por objeto hacer reflexionar a los etnógrafos sobre las precauciones que hay que adoptar en el viaje, la necesidad de seguir haciendo trabajo de campo en lugares difíciles, y sobre las habilidades sociales que el etnógrafo desarrolla de manera inconsciente, fruto de la experiencia, para afrontar la adversidad.

Abstract: Ethnographic fieldwork, as a distinctive feature of Anthropology, usually involves going out of the libraries and placing us in a context of interaction with people who are of our interest. In some methodological manuals they warn about the risks that suppose reducing the distances and diving an extended time in the life of a social group, but, for obvious reasons, there do not refer the numerous dangerous situations that can be given or to be given in the prefaces, before entering or after leaving the workplace. In the present text present a concrete case of experience lived in Venezuela in January 2006, for a robbery and kidnapping just arriving in the country with the intention of realizing field work in the High Orinoco with Yanomami communities. The narrative is intended to reflect ethnographers on the precautions to be taken on the trip, the need to continue doing field work in difficult places, and social skills that the ethnographer develops unconsciously, based on experience, to face adversity.

Palabras clave: Secuestro. Atraco. Violencia. Etnografía. Trabajo de campo Kidnapping. Robbery. Violence. Ethnography fieldwork 


\section{Introducción}

En conversación con mi amigo François Lartigue, antropólogo de origen francés residente en México D.F. e investigador del CIESAS (Centro de Investigaciones y Estudios Superiores en Antropología Social), me ponía en conocimiento de la enorme bajada que había experimentado el trabajo de campo etnográfico clásico en México, debido al miedo existente entre profesionales y estudiantes de salir al terreno y convivir por tiempo prolongado en zonas rurales con poblaciones campesinas o indígenas, no por el peligro que ellas entrañan en sí mismas sino por el que las rodea. El incremento de la violencia social, motivada especialmente por el narcotráfico, de los asesinatos, las violaciones, los secuestros o los atracos, han hecho que crezca la desconfianza en la gente, el miedo a ser víctima de alguna agresión y, en consecuencia, a evitar la calle y quedarse en casa. Circunstancia que se aprecia también en el ejercicio profesional de los antropólogos y de quienes están en vías de formación.

El trabajo interactivo y continuado de observación sistemática, participante o no, de inmersión profunda en la vida de una comunidad, desconocida para el investigador en un primer momento, cada vez se hacen más escasos, siendo sustituido por trabajos fragmentados o discontinuos, más bien en áreas urbanas, y basados principalmente en la entrevista, que permite a los investigadores regresar cada día al propio hogar. Ambos conveníamos en que, sin menospreciar ninguna técnica al uso, el trabajo intensivo y continuado en contexto de interacción era el principal distintivo metodológico de la profesión o de los estudios, y era lamentable que el alumnado egresado empiece a tener serias carencias en ese sentido por la falta de práctica.

Otro colega, Juan Luis Sariego, profesor de la ENAH (Escuela Nacional de Antropología e Historia) en Chihuahua, institución con la que estudiantes de Antropología de la Universidad de Granada habían realizado trabajo de campo por medio de intercambio universitario entre 2003 y 2007, me contaba que el alumnado de la Escuela ya había dejado de salir, generalmente a la sierra Tarahumara para hacer prácticas con las poblaciones nativas, porque no exisatía seguridad y había que evitar riesgos.

Colegas antropólogos de la UCV (Universidad Central de Venezuela) en Caracas me informan también que hace ya bastantes años que los alumnos de Antropología se gradúan sin tener la mayoría de ellos la menor experiencia de trabajo de campo, debido, no sólo a la escasez de recursos, sino al riesgo que correrían los estudiantes si tienen que aventurarse a vivir fuera de casa durante meses, si se pretende hacer al modo más clásico.

Cada disciplina académica desarrolla a lo largo de los estudios universitarios una serie de habilidades en los estudiantes con las que luego se tendrán que abrir camino en el ámbito profesional, y realmente carecer de experiencia en el trabajo de campo antropológico supone una gran laguna por la pérdida de perspectiva que implica.

Entre los manuales metodológicos de Ciencias Sociales y especialmente de los que están orientados hacia la etnografía (Aguirre, 1995; Guasch, 1997; Hammersley y Atkinson, 1994; Velasco y Díaz de Rada, 1997; entre otros), son muchos los consejos y advertencias que se pueden obtener, en cuanto a los cuidados que es preciso considerar durante la convivencia cotidiana con los demás en lugares no usuales: cuidado con el ambiente físico, con las comidas, con las relaciones sociales en la diversidad de situaciones que se presentan; todo ello con el fin de saber estar, ganarse la confianza de las personas, evitar enemistades y acceder de manera fluida a la apreciada información. En la etnografía de diferentes autores (Barley, 1989; Ravinow, 1992) se relata, en ocasiones con bastante hilaridad, las peripecias que han pasado en sus lugares de trabajo, las dificultades y prejuicios que han tenido que superar, las humillaciones que a veces han tenido que soportar; todo ello forma parte de la práctica metodológica, del proceso etnográfico, de la experiencia de vida que resulta 
ilustrativo y aleccionador para los lectores. De las obras etnológicas no sólo se desprenden avances en el conocimiento teórico de los temas que sean objeto de estudio, sino que el interés se centra también en saber cómo el investigador se las va ingeniando para "estar allî" y "producir datos". El proceso puede tener tanto o más interés que el producto.

En el presente texto voy a compartir con los lectores una experiencia personal, que en su momento escribí como ejercicio catártico y que apenas fue conocida por unos pocos amigos. Con el paso del tiempo y las conversaciones mantenidas recientemente a las que he hecho mención al principio de esta introducción, decidí publicarla con el propósito de hacer reflexionar a los etnógrafos sobre las precauciones que hay que adoptar en el viaje, la necesidad de seguir haciendo trabajo de campo en lugares difíciles, de no dejarse atemorizar ante situaciones peligrosas, y sobre la utilidad de las habilidades sociales que el etnógrafo desarrolla de manera inconsciente, fruto de la experiencia, para salir airoso ante la adversidad.

Se trata de la experiencia vivida en Venezuela en enero de 2006 con motivo de un atraco con secuestro justo al llegar al país con el propósito de realizar trabajo de campo en el Alto Orinoco con comunidades Yanomami. La narración presentada a continuación es fiel a la redactada en un principio (Samariapo, 12 de enero de 2006) con algunas correcciones sintácticas realizada posteriormente (Granada, 26 de febrero de 2006).

\section{Un atraco en la memoria ${ }^{1}$}

La vida de todo ser humano se limita, y no es poco, a acumular experiencia y obrar en consecuencia, experiencia de distinto tipo que provocan sensaciones unas veces agradables, otras veces desagradables, otras neutras; unas veces en ámbitos locales sin salir del pueblo, otras en ámbitos más cosmopolitas; en cualquier caso, imposibles de repetir, cada situación es única en sí misma. Estamos abocados a aprender por inferencia, a transferir impresiones, conocimientos, emociones de unos a otros contextos, a tomar nota y procurar enmendar errores, aunque no es fácil dejar de tropezar en los mismos o semejantes obstáculos, somos sapiens pero también olvidadizos y con frecuencia incautos.

Lamentablemente, o no, cuando parece que sabemos, aunque sea a base de errar y cumplir años, nos aproximamos a la fecha de caducidad y poco tiempo nos queda para mostrar o demostrar, aunque sea a nosotros mismos, que no somos tan torpes, que conseguimos tener cierta capacidad de respuesta ante situaciones difíciles, y especialmente ante aquellas que ponen en peligro lo que más apreciamos: la propia vida.

Los medios de comunicación en general y la televisión en particular, de una manera progresiva ha ido normalizando las miserias humanas, al extremo de no indigestársenos el almuerzo o la cena cuando lo hacemos ante una pantalla que, a su modo, nos proyecta crímenes, violaciones, maltratos, raptos, robos, las injusticias del mundo. Todo ello lo presenciamos generalmente como espectadores, de ahí la pasividad, los protagonistas de las calamidades son otros, pero ¿qué haríamos cuando el protagonista del desastre es uno mismo? ¿Qué pasaría si fuéramos secuestrados y atracados a mano armada? ¿Cómo reaccionaríamos? ¿Qué capacidad de aguante tendríamos? Sin ser ésta una gran tragedia, vamos a relatar brevemente aquí la historia de un atraco, con el deseo de que pueda servir, si cabe, para alertar a los incautos, así como de cierto consuelo a quienes inevitablemente hayan experimentado una situación parecida.

Todo ocurrió la noche del domingo 8 de enero de 2006. Un avión de la compañía Air Europa aterrizó en el aeropuerto de Maiquetía (Venezuela) a las 18:30. Tras una gran demora en la recogida del equipaje, a las 19:30 salía por fin con dos bultos: una pequeña mochila negra y una bolsa de mano marrón. Entre el derrumbe de una parte del viaducto que lleva a Caracas, el caos de tráfico existente, la entrada de la noche, y las ganas de llegar al punto

1 El título que en un principio fue: "Memoria de un atraco" ha sido modificado finalmente por sugerencia del antropólogo Antonio Pérez. 
de destino, todos nos apresuramos por salir cuanto antes del aeropuerto. Cambié $100 €$ en bolívares a un joven librecambista, que siempre sale más beneficioso que en el banco u oficina de cambio, y este mismo joven me señaló la persona que me podía llevar a Caracas, un taxista pirata, hombre de unos 30 años, aparentemente honesto. Con amabilidad, fue él quien se ofreció a llamar al hotel El Conde ante mi necesidad de hacerlo para reservar habitación:

$(\mathrm{S} 1)^{2}$ “HHotel El Conde? ¿Tiene habitación sencilla? ¿Cuánto es? ... 45.000 la noche. ... Una reserva a nombre de ... Ángel Acuña”.

$(\mathrm{A})^{3}$ "Gracias, muy amable", le dije.

Acordamos el precio del transporte en 20 dólares y nos encaminamos al taxi, no obstante, para asegurarme de la fiabilidad de su llamada, antes de introducir el equipaje lo paré:

"amigo, déjeme por favor que llame al hotel para asegurarme que no hay error en el precio".

(S1) "Como no, dígame el número".

Le di el número y él mismo lo marcó (gran error, ya que fue otro el número marcado). Quien se puso al otro lado respondió: "hotel El Conde", confirmándome la reserva y el precio. Así y todo me quedó una sombra de duda, pero, sin pensarlo decidí seguir adelante y subir al vehículo.

Sentado en la parte de atrás, con la mochila conmigo y el bolso de mano en el maletero cerré la puerta y emprendimos el camino. Al estar cortada la vía normal por el viaducto, la ruta a seguir no me era familiar, salimos a la derecha del aeropuerto, vía Carayaca.

(S1) “¿Está bien el aire señor?”... “¿De dónde viene señor?”... “¿Viene para mucho tiempo?”... ¿ ¿Turismo o trabajo?”... “¿Disculpe, profesor de qué es usted?"

Demasiadas preguntas en tan poco tiempo, lo que unido al aspecto hermético del coche con los cristales totalmente negros que impedían desde fuera ver lo que había en su interior, me causó un mal presentimiento. Un coche estacionado en el arcén con el capó levantado y cinco hombres a su alrededor, en una carretera casi solitaria, confirmó la sospecha.

(S1) "A ver qué problema tienen estos panas (amigos)".

Inmediatamente probé abrir la puerta y comprobé que tenía el seguro echado. De repente abordaron nuestro vehículo, uno se sentó junto al conductor y otro junto a mí. ¡Empezó la fiesta!.

$(\mathrm{S} 2)^{4}$ "Somos la guerrilla, colabore y no le pasará nada, si no colabora le meto un tiro y está muerto".

Estas palabras fueron las primeras que pronunció el cabecilla sentado al lado del conductor y vuelto hacia mí, mostrándome en la mano izquierda una placa identificativa que vi fugazmente y una pistola en la derecha que en ese momento me apuntaba al pecho.

(S2) "Deme el pasaporte”... “Qué vino a hacer en Venezuela? ... Vino por coca, verdad?".

2 Secuestrador 1

3 Ángel

4 Secuestrador 2 
Para no enredar demasiado mi historia y hacerla más comprensible dije que venía invitado por el ICAS (Instituto Caribe de Antropología y Sociología) para realizar un curso y estaría en Caracas dos semanas (realmente venía para continuar mi trabajo de campo en el Alto Orinoco en relación con un proyecto de investigación sobre la construcción social y cultural del cuerpo en la sociedad yanomami). Hecha la presentación fueron ya al grano.

(S2) “ ¡Deme la cartera, ... deme todo el dinero, ... le dije todo el dinero, vamos démelo! ... No me mienta, colabore y no le pasará nada”.

Una y otra vez el cabecilla insistía en esos términos y tras darle un total de $800 €$ (entre euros, dólares y bolívares), insistía por mi parte en que no tenía nada más.

Sin moverme del asiento y siempre con las manos cruzadas encima de las piernas, me registraron camisa y pantalón. Luego registraron la mochila a fondo y no encontraron más dinero. El acompañante que tenía al lado controlaba mis movimientos y me tranquilizaba en la idea de que colaborase, que me dejarían todo mi equipaje y material de trabajo para que pudiera realizar lo que había venido a hacer.

$(\mathrm{S} 3)^{5}$ "Ves, aquí están tus papeles, tus lápices, no falta nada, ¿verdad?".

Mostraba cierta complicidad conmigo, se manifestaba comprensivo con mi situación pero me advertía que las amenazas iban en serio. Amenazas de muerte por la falta de colaboración que pronunciaba el cabecilla apuntando de vez en cuando con una pistola mi cabeza. El conductor se mantenía normalmente callado aunque cuando hablaba se expresaba con suma dureza:

(S1) “¡Te vamos a dar un tiro y dejar por aquí!".

Así pasaron aproximadamente 45 minutos, hasta que el cabecilla, incrédulo de que no tuviera más dinero me separó del asiento y metiéndome la mano por detrás del pantalón descubrió lo que con tanta tensión había ocultado hasta ese momento, una bolsa elástica ajustada por detrás a la cintura con $900 €$ en su interior. Tirando de ella con fuerza preguntó:

(S2)“¿y esto que es? ¿Qué es esto?”.

(A) "Es mi última reserva, si se la doy no sé qué hacer".

Les pedí por favor que no me dejaran sin nada de dinero, que no podía seguir así.

(S2) "No has colaborado, has mentido todo el rato y te vas a morir".

El conductor se metió por una carretera sin tráfico en descampado y le decía al compañero que me sacara y me diera un tiro que es lo que merecía.

(S1) "Dale un tiro ya, es un mentiroso".

Les pedí por favor que no lo hicieran, que tenía que protegerme, pero que ahora sí que no me quedaba nada, que lo tenían todo (1.700€); todo ello ante el mayúsculo enfado que tenían, incluido mi acompañante de al lado que hasta ese momento había jugado el papel de blando.

(S2) "Esta es la última oportunidad que te doy, la última, dame el resto o aquí te mueres. Sabemos que traes 10.000 dólares, tenemos contacto con la INTERPOL y sabemos quién eres".

Esas palabras me confirmaban que no sabían nada de mí, que mi encuentro con ellos se debió a la mala suerte y a mi incauta decisión de subir al coche de un desconocido no identificado. Ellos hacían su papel y yo debía seguir haciendo el mío de la mejor manera para salvar la vida. En esas circunstancias era preciso desempeñar adecuadamente el papel de 
victima, hacerse cargo de la situación, actuar con naturalidad, con calma, sin nerviosismo, sin exagerar la pena, ni mantenerse demasiado confiado y menos aún altanero o soberbio. Sobre todo había que evitar en ellos que subiera el nivel de enfado y nerviosismo, tenían pistolas y podían disparar.

Tras mucho insistir parece que se convencieron de que no tenía ningún dinero más, ya había tensado demasiado la situación manteniendo oculto la mitad del dinero y tal como estaban los ánimos hubiera sido un suicidio arriesgar más. Realmente ya habían encontrado todo el dinero en efectivo y algo más de lo que también querían sacar provecho y en lo que estuvimos ocupados casi una hora: la visa. Dentro de la bolsa con el dinero se encontraba una visa que apenas había utilizado en los últimos tres años. Se empeñaron en que les diera el número pin (clave) que por fuerza debía saber, con la intención de sacar el dinero a través de un cajero automático. No había manera de convencerles de que no tenía ese número, realmente no lo sabía, les dije que tan sólo usaba la tarjeta en caso de necesidad como último recurso para pagar un hotel o sacar dinero del banco, siempre acompañado del pasaporte, y que sólo podía sacar yo.

(S2) "Sigues diciendo mentira, ... Ya no te creemos. Dime ya el número pin o te disparo" (apuntándome con la pistola la rodilla).

Pasada ya una media hora de dimes y diretes sobre el mismo tema, opté por no insistir más, guardé silencio diciéndoles antes: "hagan lo que quieran conmigo, les he dado todo y la tarjeta no tiene código pin".

Fueron ellos quienes sacaron el tema de mi familia, de que no la iba a ver más, que tendría una familia feliz y no iba a ver más a mis hijos. Trataron de hacerme ver lo mucho que perdería con la vida. Por mi parte, sin insistir demasiado, procuré hacerles entender que efectivamente era mucho lo que me iban a quitar si me mataban, para entenderlo sólo tenían que ponerse en mi lugar, pero lo iban a hacer sin motivo alguno.

(A) "Soy una persona, una persona como ustedes y deseo seguir viviendo. Ya tienen todo el dinero que llevaba encima, por favor, déjenme ir".

No fue de inmediato, pero a partir de ahí la situación se fue calmando. Una vez más me preguntaron por el número pin.

(A) "No hay número pin, me están pidiendo algo imposible".

En varias ocasiones habían insistido en que ellos no eran delincuentes.

(S1) "No somos hampa, somos la guerrilla".

Aunque no sé bien a qué se referían, ni estaba en disposición de preguntar.

(S1) "Si hubieras caído en manos del hampa te hubieran dado un tiro y te habrían soltado por ahí, se llevarían todo".

(S2) "Tome su cartera".

Vacía, claro está, me dijo el cabecilla alargándomela con la mano. Mientras el acompañante sentado a mi lado me hacía ver que mis cosas estaban todas en la mochila, que no faltaba nada, el cabecilla, identificándose como teniente, con mi pasaporte en una mano y el celular en la otra llamó a un supuesto coronel y le fue dictando mi nombre y número de pasaporte, después de conversar unos minutos y decirle que no había colaborado y que preparase un kilo de cocaína para infiltrarla en mi equipaje cuando estuviera en el aeropuerto y no saliera del país si me iba de la lengua.

(S2) "Tú conoces como son las cárceles aquí, si denuncias esto o hablas con alguien la vas a conocer y no volverás a tu casa más nunca, te vamos a tener controlado todo el tiempo y sabemos lo que haces". 
A continuación me dieron el pasaporte y la visa, anunciándome que me dejarían junto a un hotel, me darían dinero para quedarme esa noche y por la mañana agarrara un taxi al aeropuerto. Así lo hicieron, pasamos por la puerta de un motel ("Silvepe" en Catia la Mar), allí se bajó el cabecilla mientras dábamos una vuelta más con el coche, al pasar de nuevo por el lugar se detuvo, me metieron unos billetes en el bolsillo de la camisa (100.000 bolívares equivalentes a unos 30 euros) y me indicaron que saliera del vehículo, recogiera los dos bolsos y caminara derechito, como si nada hubiera pasado, hacia el motel, sin mirar atrás.

(S2) "Te estoy apuntando todo el rato, si haces algo raro te disparo".

Afortunadamente me devolvieron también la botella de vino que le llevaba de regalo a la señora María, de Puerto Ayacucho, a quien le gustó mucho cuando lo probó.

Ahí acabó el atraco tras algo más de dos horas de secuestro. Con cara ... no sé de qué, el recepcionista me dio un cuarto en el motel, mirándome con sorpresa, ya que lo normal era llegar con vehículo propio e ir acompañado de alguna amante. Se trataba de un motel discreto que más parecía un parking público, con guarda de seguridad incluido. La habitación era confortable, limpia, con una gran cama de matrimonio que ocupaba casi todo el espacio, dos mesitas a los lados, un espejo enfrente para verse de cuerpo entero, un televisor en alto y un aseo pequeño pero decente. Sentado en la cama, perplejo me miré al espejo unos segundos y decidí que mejor me daba una ducha. Pensé en salir a llamar a los amigos de Caracas pero, tras todas las amenazas recibidas dejé que pasara la noche para llamar desde otro lugar más seguro, ya en la mañana. Dejé las cortinas abiertas para despertarme con los primeros rayos de sol y dormí profundamente. Por cierto, durante la madrugada me despertó el sonido de unas llaves hurgando en la cerradura de la puerta, eran amantes confundidos de número por los deseos carnales, menos mal.

$\mathrm{Al}$ amanecer, dos taxis se encontraban estacionados en la parada existente junto al motel, tomé uno de ellos y no tardamos más de 15 minutos en llegar al aeropuerto. Conversé normalmente con el taxista (éste sí lo era), hablamos del tráfico, del viaducto, de la carestía de la vida; en ningún momento mencioné nada de la noche anterior pero, por cómo nos mirábamos creo que lo intuía. Ya en el aeropuerto, contacté por teléfono con Gabriela y Miguel Ángel, amiga y amigo, además de directora y director de sendas instituciones que me prestarían su ayuda y una colaboración decisiva para segur adelante con los planes.

Reflexionando sobre la identidad de los atracadores, por el trato recibido, cargado de amenazas pero sin golpes, dejándome finalmente en un lugar seguro; por el botín substraído, casi exclusivamente de dinero, permitiéndome conservar el resto del equipaje y material de trabajo; por la manera precisa de manejar el pasaporte y de hablar, me dejaron la impresión de no ser delincuentes comunes, de no ser el hampa pura y dura que, como ellos mismos me indicaron, hubieran acabado conmigo sin preguntar y se lo habrían llevado todo tras abandonarme; la guerrilla, sin embargo, no me cuadraba, ¿qué guerrilla?, no estábamos en Colombia, y además no era el sitio más adecuado para que operen; aún así, un aire policial o militar sí que me dieron y, como posteriormente las conversaciones con amigos venezolanos me vinieron a confirmar, lo más probable es que se tratara de una de las muchas bandas de ex-agentes de la seguridad del Estado que, desprovistos de empleo, se han organizado mafiosamente para dedicarse al robo y a la extorsión.

Aquella noche, tumbado en la cama rebobiné toda la trama y una borrachera de sensaciones se mezclaban en mi mente. Como no fue poco lo recibido, para castigarme algo más pensé que me lo merecía, que los errores se pagan y ese fue bastante grueso. Al mismo tiempo y como recurso psicológico, de manera imaginaria retrocedía en el tiempo y pensaba que acababa de llegar al aeropuerto de Maiquetía, que tomaba el taxi correcto (el oficial), que todas mis pertenencias estaban intactas; qué distinto sería, pero era pura fantasía; volvía de nuevo a la realidad y hacía memoria de todos los pequeños detalles sospechosos que 
debía haber considerado para desistir de entrar en el coche, ya era tarde para rectificar, en cualquier caso. Revisé el equipaje y, aunque lo dejaron casi intacto, faltaba una grabadorareproductora minidisc, casualmente el objeto más valioso que tenía en ese momento, ya que con ella debía no sólo grabar nuevos testimonios y cantos en el trabajo de campo, sino y sobre todo reproducir y traducir las siete cintas grabadas de la estancia anterior. Las pérdidas reales fueron $1.700 €$, la grabadora-reproductora minidisc (valorada en unos $400 €$ ), un pendrive (de unos $80 €$ ) lleno de información, y algunas pilas y bolígrafos. Valoré la situación y me convencí de que las pérdidas habían sido económicas y materiales pero no impedían seguir adelante, tenía recursos para hacerlo: material de trabajo y amigos/as que podían sacarme del apuro, además de la visa. Convencido de que materialmente seguir adelante con los planes era posible, faltaba algo esencial para hacerlo: el ánimo. Si no perdido, se hallaba muy escondido y no fue fácil encontrarlo y darle salida. En contraste a la actitud de autocastigo que me decía merecer lo recibido, por otro lado sentía que no lo merecía, que era demasiada inversión de energía, de tiempo, de esfuerzo económico, de ilusión, para acabar así; pero claro, eso de haber acabado era un decir. Yo tenía la decisión de hacerlo y ni había acabado, ni estaba acabado, el proyecto que me traía a Venezuela estaba casi recién empezando y era suficientemente persuasivo para no abandonar, ni siquiera en ese momento. Apesadumbrado, con una sensación de vacío interno y confusión, disgustado por la herida recibida al orgullo personal por haber sido engañado inocentemente con tanta experiencia acumulada en más de 25 años de salidas a otros países, pensé que la única opción que tenía era seguir siempre adelante hasta donde pudiera, no pensar por un momento en abandonar. Como en el duelo por una persona querida, el ánimo va subiendo con el tiempo, es una actitud mental, y la cosa realmente no era tan grave, sencillamente había sufrido un atraco con secuestro, uno de tantos que se producen en el mundo, una más de las calamidades que nos muestra la tele, con la diferencia de que el "otro" ahora era "yo". Pero, si podía seguir almorzando con las imágenes o noticias de guerras infames, de cuerpos desmembrados por atentados, de asesinatos por celos, o de linchamientos de mendigos en la calle, cómo me iba a venir abajo por esta minucia.

Este hecho, lamentablemente nada aislado, es sin duda consecuencia de la injusticia social que nos envuelve, el tributo que hay que pagar por vivir y consentir un mundo con desigualdades extremas, pero este pensamiento no me llevó a adoptar una actitud caritativa con los delincuentes, co-protagonistas de este relato, pensando que lo necesitaban más que uno. Tal vez fuera así, pero lo que hicieron merece un buen correctivo, correctivo que deben decidir los tribunales si los encuentran, es su responsabilidad. La nuestra, la de las víctimas, es aprender la lección, no ser tan confiados, actuar con más prudencia, y por supuesto no perder el ánimo, es lo que podemos conservar, aunque nos cueste, dentro de la propia piel sin que los malhechores lo vean. La vida no tiene por que ser un valle de lágrimas, aunque nos empeñemos en ello y nos la hagamos difícil. Es realmente lo único que tenemos, lo demás son envoltorios superfluos y, mientras se conserve, si usamos razonablemente la inteligencia que tengamos (mucha o poca, no importa), es muy conveniente sentirnos contento por mantenerla, pese a todo. Sin ella, sin vida, como decía Peter Pan, solo nos queda ser "polvo de estrellas".

Samariapo, 12 de enero de 2006

Granada, 26 de febrero de 2006

\section{Bibliografía}

AGUIRRE BELTRÁN, Ángel (Ed.)

1995 Etnografía. Metodología cualitativa en la investigación social. Barcelona: Marcombo. 
BARLEY, Nigel

1989 El antropólogo inocente. Barcelona: Anagrama.

GUASCH, Oscar

1997 Observación participante (cuadernos metodológicos). Madrid: C.I.S.

HAMMERSLEY, Martyn y ATKINSON, Paul

1994 Etnografía. Métodos de investigación. Barcelona: Paidós.

RAVINOW, Paul

1992 Reflexiones sobre un trabajo de campo en Marruecos. Madrid: Júcar Universidad.

VELASCO, Honorio y DÍAZ DE RADA, Ángel

1997 La lógica de la investigación etnográfica. Un modelo de trabajo para etnógrafos de la escuela. Madrid: Editorial Trotta.

\section{3}

